\title{
CURRENT STATUS OF L-BAND ELECTRON ACCELERATOR FOR IRRADIATION SOURCE*
}

\author{
S. H. Kim\#, H. R. Yang, M. Cho, and W. Namkung \\ Department of Physics, POSTECH, Pohang 790-784, Korea \\ S. D. Jang, Y. G. Son, S. J. Kwon, S. J. Park, and J. S. Oh \\ PAL, POSTECH, Pohang 790-784, Korea
}

\begin{abstract}
An intense L-band electron accelerator is designed and under development for CESC (Cheorwon Electron-beam Service Center) irradiation applications. It is capable of producing $10-\mathrm{MeV}$ electron beams with average $30 \mathrm{~kW}$. For an RF source, a Thales klystron is used with $1.3 \mathrm{GHz}$, pulsed $25 \mathrm{MW}$, and average $60 \mathrm{~kW}$. The accelerator column, fabricated by IHEP in China, is operated with $2 \pi / 3$ mode traveling-wave under the fully-beam-loaded condition. The modulator was fabricated with inverter power supplies. The klystron was assembled to the klystron tank with pulse transformer. The high-voltage pulse test was conducted for the klystron tube. In this paper, we present design details of the accelerator and current status.
\end{abstract}

\section{INTRODUCTION}

Recently, demands on the electron linear accelerator are increased for industrial applications [1]. In using electron as an irradiation source, the higher beam energy is favorable since the penetration depth is larger, as shown in Figure 1. However, the electron beam energy is limited by about $10 \mathrm{MeV}$ due mainly to neutron production. For the clinical X-ray systems, a low current and a low repetition rate are required. The X-ray source for the container inspection requires $5-10 \mathrm{MeV}$ with a few kilowatts of the average beam power [2]. On the other hand, the food or waste sterilization system requires relatively high average beam power since the process speed is proportional to it [3].

A high average-power electron accelerator is being developed in the institutional collaboration of between PAL/POSTECH and KAPRA. The accelerator will be installed at CESC and it will be used for not only for sterilizing foods and medical products, but also reforming materials. The accelerator is required to provide an average beam power of $30 \mathrm{~kW}$ at the beam energy of 10 $\mathrm{MeV}$. In order to achieve such a high beam power, the RF frequency is determined as $1.3 \mathrm{GHz}$ for a higher pulsed RF power. Since the beam current is also high, the L-band travelling-wave accelerating structure is designed with the beam-loading effect.

\footnotetext{
*Work supported by KAPRA

"khan777@postech.ac.kr
}

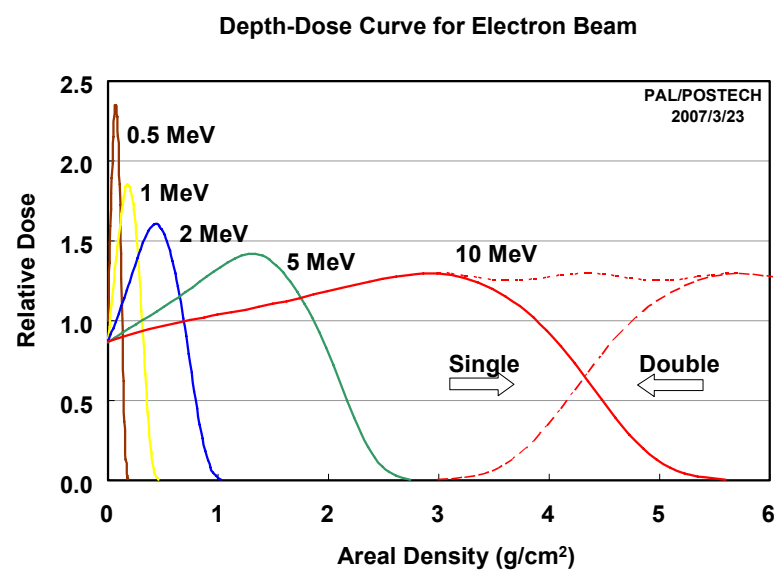

Figure 1: The depth-dose curve for electron beam. The "double" means that the beam is also injected from opposite side.

\section{ACCELERATOR SYSTEM}

The accelerator system is mainly divided by a power supply part, a RF system, and a beamline. Components, inside the hashed boxes in Figure 2, are the power supply parts. They supply high-voltage or high-power to the klystron and the E-gun. To supply a $264-\mathrm{kV}$ beam voltage with a beam current of 230 A to the klystron tube, a pulse modulator and a pulse transformer is developed by PAL. The modulator mainly consists of a set of inverter power supplies, a pulse forming network (PFN), and a thyratron switch. The inverter power supplies are totally 8 units, each of $45 \mathrm{kV}$ and average $30 \mathrm{~kW}$. The PFN has 15 stages, each with a $50-\mathrm{nF}$ capacitor and a $2.2-\mu \mathrm{H}$ inductor. CX2412X is used for the thytratron switch. The pulse length is $10 \mu \mathrm{s}$ and the repetition rate is $350 \mathrm{~Hz}$, as presented in Table 1.

The RF-line includes the klystron (Thales TV2022D) and waveguide network. The klystron amplifies the RF power to pulsed $25 \mathrm{MW}$ from the source RF generator of $1.3 \mathrm{GHz}$. It delivers RF to the accelerating column through the L-band waveguide network. Since the column is a travelling-wave structure, the matched load is attached after the output of the column. Since the prebuncher needs a few kilowatts of RF power, the coaxial line is branched from the waveguide line, by amount of $-38 \mathrm{~dB}$. 


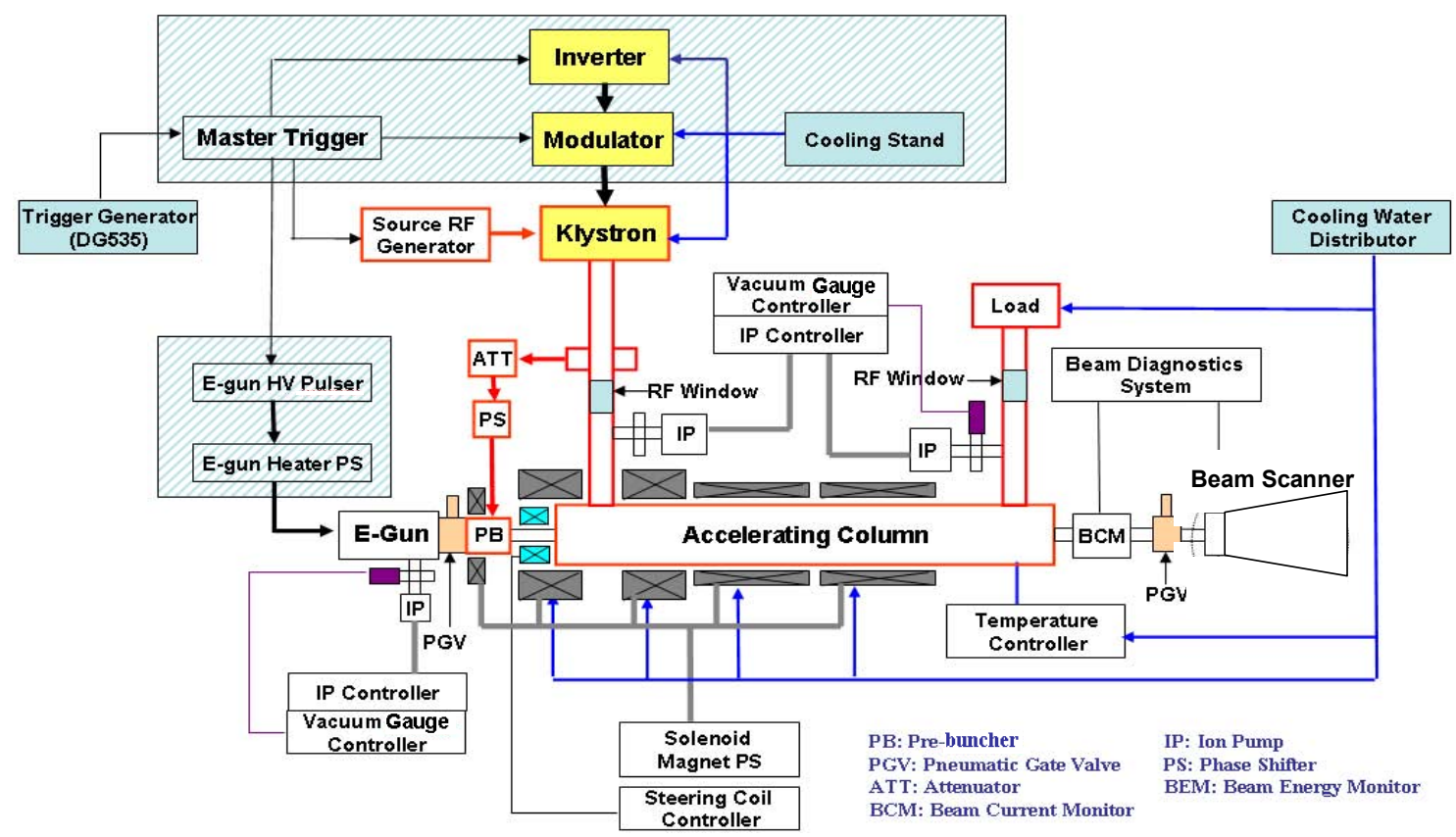

Figure 2: Block diagram of the accelerator system.

Table 1: Accelerator Parameters

\begin{tabular}{l|r}
\hline \multicolumn{2}{c}{ Accelerator Parameters } \\
\hline \hline Operating Frequency & $1.3 \mathrm{GHz}$ \\
Pulsed RF Power & $25 \mathrm{MW}$ \\
RF Pulse Length & $7 \mu \mathrm{s}$ \\
Repetition Rate & $350 \mathrm{~Hz}$ \\
Averaged RF Power & $60 \mathrm{~kW}$ \\
E-gun High Voltage & $-80 \mathrm{kV}$ \\
Pulsed E-gun Current & $1.6 \mathrm{~A}$ \\
Beam Pulse Length & $6 \mu \mathrm{s}$ \\
Beam Energy & $11 \mathrm{MeV}$ \\
Output Beam Current & $1.4 \mathrm{~A}$ \\
Beam Transmission Rate & $87 \%$ \\
Averaged Beam Power & $33 \mathrm{~kW}$ \\
Shape of Accelerating Cell & $\mathrm{Disk}-1 \mathrm{oaded}$ \\
Operating Mode of Accelerator & $2 \pi / 3 \mathrm{mode}$ \\
RF Filling Time & $0.8 \mu \mathrm{s}$ \\
Operating Temperature & $40^{\circ} \mathrm{C} \pm 1^{\circ} \mathrm{C}$ \\
Averaged Accelerating Gradients & $6.8 \mathrm{MV} / \mathrm{m}$ \\
Beam Loading Factor & $-4.7 \mathrm{MeV} / \mathrm{A}$ \\
Temperature Shift Factor & $-2.3 \mathrm{MeV} / 1^{\circ} \mathrm{C}$ \\
\hline
\end{tabular}

The material of the waveguide is aluminium, fabricated by MEGA. These waveguide is filled with SF6 gas. Between the pressurized region and the vacuum region, there is an RF window, Thales TH20141A. The gas pressure should be maintained as $1.5 \mathrm{~atm}$.
The beamline is where the electron beam passes through. Therefore the pressure should be maintained under $10^{-8}$ Torr. Two ion pumps of $240 \mathrm{l} / \mathrm{s}$ are connected to the vacuum-side waveguide, as shown in Figure 2. The E-gun has a $20-l / \mathrm{s}$ ion pump for itself to protect the cathode surface.

The accelerating column with the pre-buncher is designed by POSTECH. With a 25-MW input RF power, the column can produce $11 \mathrm{MeV}$ at the beam current of 1.4 A, the fully-beam-loaded condition [4]. The input RF power into the pre-buncher is adjusted for the maximum output beam power by the attenuator and the phase-shifter. Every kind of cavities in the column is tested with prototype cavities [4]. The actual column is being fabricated by IHEP, China.

There are 5 solenoids along the beam line. The magnetic field is determined for the electron beam enough to clear both of the beam aperture and the drifttube wall [4]. The first solenoids-magnet is powered by a 3.6-A and 5.6-V DC power-supply. The rest are connected serially and powered by a $32-\mathrm{A}$ and $250-\mathrm{V}$ DC power supply. Two sets of the steering coil are placed on the middle of the drift tube, as shown in Figure 2. A 1.6-A and $4-\mathrm{V}$ DC power is supplied to the steering coil to correct the beam angle up to $13^{\circ}$.

The cooling water is supplied to the inverter power supply, the modulator, the collector and the focusing magnet of the klystron, the solenoids magnet on the column, the matched load, and the accelerating column. The temperature controller is able to maintain the temperature on the column cavity, within $40^{\circ} \mathrm{C} \pm 1^{\circ} \mathrm{C}$. The flow-rate of the cooling water, injected into the cooling jacket on the column, is determined as $200 \mathrm{l} / \mathrm{min}$. In this case, the cavity temperature distribution is shown in Figure 3. 


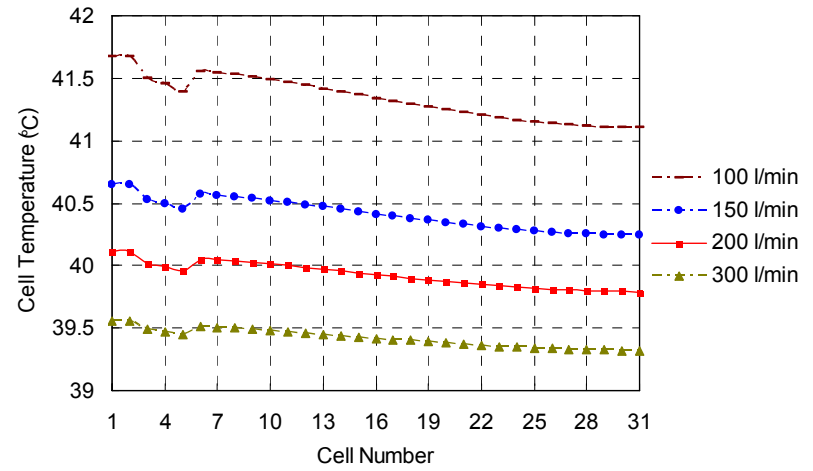

Figure 3: The temperature of the accelerating column with the cooling water.

\section{STATUS AND PLAN}

The fabrication of the modulator was finished and the klystron tube was assembled to the tank. The high-voltage pulse test is conducted for the klystron tube, early in the June. The result is presented in Figure 4. The PFN will be tuned to get the even flat top and enough flat top width.

The accelerating column will be delivered soon, and then other beamline components will be assembled to the accelerating column. The waveguide and coaxial line is ready to be installed at CSEC. The installed high-power $\mathrm{RF}$ system in the CESC site is shown in Figure 5.

The beam scanner, cooling system, and control system under development in parallel. The beam commissioning is planned to be conducted in this year.

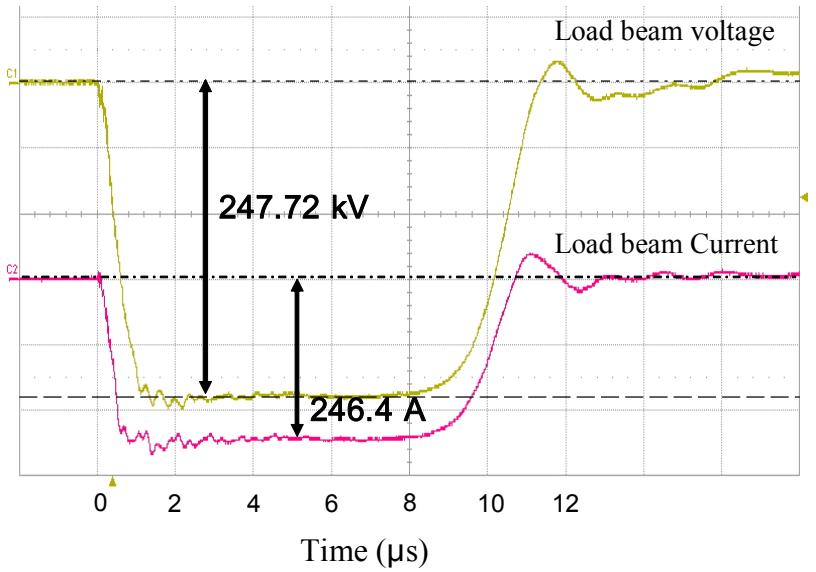

Figure 4: The high-voltage pulse test for the klystron tube.

\section{ACKNOWLEDGEMENT}

The authors are appreciated to Prof. Luo Yingxiong at IHEP, Beijing for useful discussions on general issues of the accelerator system and the design of the accelerating column.

\section{REFERENCES}

[1] A. M. M. Todd, "Emerging Industrial Applications of Linacs," in Proc. Intl. LINAC Conf. (Chicago, IL, August 23-28, 1998), 1036 (1998).

[2] V. Pirozhenko, V. Belugin, A. Mischenko, N. Rozanov, B. Sychev, V. Vetrov, Y. Kokorovets, V. Ryzhikov, N. Shumeiko, S. Yatsenko, A. Korolev, K. Simonov, V. Eylan, "Complex for X-ray Inspection of Large Containers," in Proc. of EPAC 2006 (Edinburgh, Scotland, June 26-30, 2006), 2388 (2006).

[3] Y. Kamio, "10 MeV $25 \mathrm{~kW}$ Industrial Electron Linacs," in Proc. Int. Linac Conf. (Geneva, Switzerland, Aug. 26-30 1996), 836 (1996).

[4] S. H. Kim, B. Park, S. I. Moon, H. R. Yang, S. D. Jang, Y. G. Son, S. J. Park, J. S. Oh, M. H. Cho, and W. Namkung, J. Korean Phys. Soc. 50, 1416 (2007).

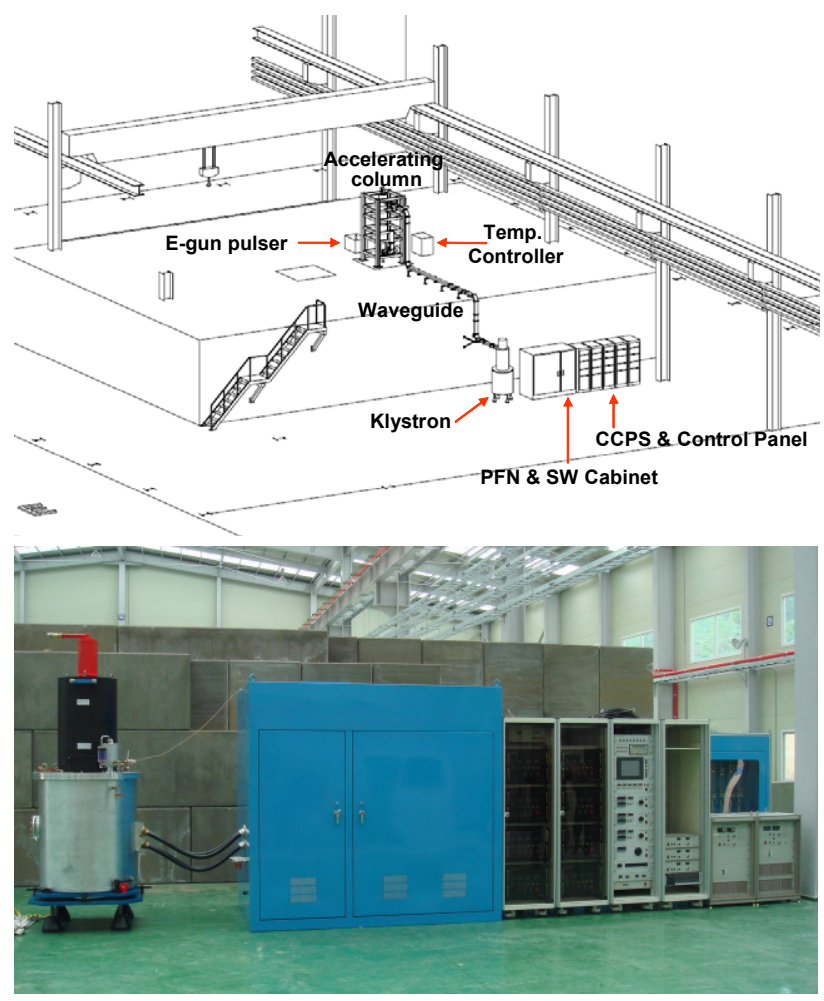

Figure 5: The drawing of the accelerator setup at the CSEC site and picture of the installed high-power RF system. 